\title{
Neoadjuvant Chemotherapy with Capecitabine, Oxaliplatin and Bevacizumab Followed by Concomitant Chemoradiation and Surgical Resection in Locally Advanced Rectal Cancer with High Risk of Recurrence - A Phase II Study
}

\author{
WOLFGANG EISTERER ${ }^{1 *}$, GUDRUN PIRINGER $^{2 *}$, ALEXANDER DE VRIES $^{3}$, \\ DIETMAR ÖFNER ${ }^{4}$, RICHARD GREIL ${ }^{5}$, JÖRG TSCHMELITSCH ${ }^{6}$, HELLMUT SAMONIGG ${ }^{7}$, \\ LIDIJA SÖLKNER $^{8}$, MICHAEL GNANT ${ }^{9}$ and JOSEF THALER ${ }^{2}$ \\ On behalf of the Austrian Breast and Colorectal Cancer Study Group \\ ${ }^{1}$ Department of Internal Medicine, Klinikum Klagenfurt am Wörthersee, Klagenfurt, Austria; \\ ${ }^{2}$ Department of Internal Medicine IV, Wels-Grieskirchen Medical Hospital, Wels, Austria; \\ ${ }^{3}$ Department of Radiotherapy and Radio-Oncology, Feldkirch Hospital, Feldkirch, Austria; \\ ${ }^{4}$ Department of Visceral-, Transplant and Thoracic Surgery, \\ Center of Operative Medicine, Innsbruck Medical University, Innsbruck, Austria; \\ ${ }^{5}$ Department of Internal Medicine III, Paracelsus Medical University, Salzburg, Austria; \\ ${ }^{6}$ Department of Surgery, St. Veit Hospital, Sankt Veit an der Glan, Austria; \\ ${ }^{7}$ Department of Internal Medicine, Medical University, Graz, Austria; \\ ${ }^{8}$ Austrian Breast and Colorectal Cancer Study Group, Vienna, Austria; \\ ${ }^{9}$ Department of Surgery and Comprehensive Cancer Center, Medical University, Vienna, Austria
}

\begin{abstract}
Aim: To evaluate feasibility and safety of neoadjuvant chemotherapy with capecitabine, oxaliplatin and bevacizumab followed by concomitant standard chemoradiation and surgical resection in patients with highrisk locally advanced rectal cancer. Patients and Methods: Magnetic resonance imaging (MRI)-defined high-risk cT3/4 rectal cancer patients were treated with 3 cycles of neoadjuvant chemotherapy with capecitabine $\left(1,000 \mathrm{mg} / \mathrm{m}^{2}\right.$ twice daily days 1-14, 22-35, 43-56), oxaliplatin (130 $\mathrm{mg} / \mathrm{sqm}$ on days $1,22,43)$ and bevacizumab $(7.5 \mathrm{mg} / \mathrm{kg}$ on days $1,22,43)$ followed by capecitabine $\left(825 \mathrm{mg} / \mathrm{m}^{2}\right.$ twice daily on radiotherapy days week 1-4) concomitantly with radiotherapy (1.8 Gy daily up to 45 Gy in 5 weeks) and surgical resection by total mesorectal excision. Feasibility, safety, response rate and postoperative morbidity were
\end{abstract}

\footnotetext{
*These Authors contributed equally to this study.

Correspondence to: Dr. Gudrun Piringer, Klinikum WelsGrieskirchen, Department of Oncology, Grieskirchnerstraße 42, A4600 Wels, Austria. Tel: +43 0724241592175, Fax: +43 072424153954, e-mail: gudrun.piringer@ hotmail.com
}

Key Words: Neoadjuvant chemotherapy, rectal cancer, capecitabine, oxaliplatin and bevacizumab. evaluated. Results: Twenty-five patients were recruited. Median age was 62 years (range $=24-78$ years) and all patients had Eastern Cooperation Oncology Group (ECOG) performance status 0. From all patients, $79.2 \%$ finished neoadjuvant chemotherapy. Twenty patients underwent surgery. Pathologic complete remission rate, $R 0$ resection and T-downstaging were achieved in 25\%, 95\% and $54.2 \%$ of the "intention to treat" (ITT) patients. The most common grade 3 adverse events (AEs) during neoadjuvant chemotherapy were diarrhea (16.6\%) and mucositis (12.5\%). In one patient, a grade 4 acute renal failure occurred (4.2\%). During chemoradiation, skin reactions (5.3\%) were the most common grade 3 AEs. Two major perioperative complications required re-intervention. Conclusion: Neoadjuvant chemotherapy with bevacizumab, capecitabine and oxaliplatin followed by concomitant standard chemoradiation is feasible in patients with high-risk locally advanced rectal cancer (LARC) and resulted in complete pathologic remission $(p C R)$ rate of $25 \%$ and neoadjuvant chemotherapy completion rate of $80 \%$.

Colorectal cancer is the most common gastro-intestinal malignancy and the second leading cause of mortality in Western countries. Overall, 33-50\% of these new cases are localized in the rectum. Neoadjuvant chemoradiation followed by total mesorectal excision (TME) is the standard 
treatment for locally advanced rectal cancer (LARC) (clinical TNM stage II-III) (1). Despite optimized local treatment with recurrence rates less than $10 \%$, neoadjuvant chemoradiation has not consistently improved overall survival (OS) and distant metastases still occur in $25-30 \%$ (2-6). Furthermore, there is only a $3-4 \%$ survival benefit with fluoropyrimidinebased adjuvant chemotherapy (7) and more than $50 \%$ of patients treated with chemoradiation do not complete adjuvant chemotherapy after TME. Efforts to improve these results have focused on more effective radiosensitizing therapies. The addition of oxaliplatin or targeted therapies has proven unsuccessful with increased toxicities (8-17). In recent years, studies investigated neoadjuvant chemotherapy followed by chemoradiation and surgical resection. This approach that seems to be feasible resulted in higher chemotherapy completion rates compared with adjuvant chemotherapy (18-20). In order to improve these results, addition of targeting agents into neoadjuvant regimen offers a rational approach. In particular, bevacizumab has demonstrated synergistic activity with both chemotherapy and radiotherapy (RT) and, thus, may represent a suitable component in the neoadjuvant treatment (21).

The aims of this study were to assess feasibility and safety of neoadjuvant chemotherapy with capecitabine, oxaliplatin and bevacizumab followed by concomitant standard chemoradiation with capecitabine and TME in patients with magnetic resonance imaging (MRI)-defined high-risk cT3/4 LARC. Secondary end-points were downstaging, histopathological response and postoperative morbidity.

\section{Patients and Methods}

Medical ethics committees of all participating centers approved the trial and all patients provided written informed consent (EudraCTNo: 2010-024354-11). This study was conducted by the Austrian breast and colorectal cancer study group (ABCSG).

Eligibility criteria. Patients with histopathologically confirmed MRI-defined cT3NxM0 (involvement of the mesorectal fascia $\leq 5$ $\mathrm{mm}$ ) and cT4NxM0 (with curative intention) adenocarcinoma of the rectum were eligible. Other key eligibility criteria included: $18-80$ years, no previous chemotherapy, RT of the pelvis or abdomen and surgical resection for rectal cancer, adequate metabolic, hematological, renal and hepatic functions, international normalized ratio (INR) and activated partial thromboplastin time (aPTT) $\leq 1.5$ upper limit of normal (ULN), WHO performance status grade $0-2$, negative pregnancy test and willingness to use highly effective methods of contraception during treatment and for 3 months after the end of treatment. We excluded patients with (a) cT1-2, cT3 (involvement of the mesorectal fascia $>5 \mathrm{~mm}$ ) rectal cancer, (b) prior malignancies (except non-melanoma skin carcinoma or in situ cervix cancer), (c) contraindication for application of capecitabine, oxaliplatin or bevacizumab, (d) clinically significant cardiovascular disease (including myocardial infarction or stroke $<6$ months before registration, unstable angina, symptomatic congestive heart failure New York Heart Association (NYHA) II-IV, serious uncontrolled cardiac arrhythmia, uncontrolled hypertension (systolic $>150$ $\mathrm{mmHg}$, diastolic $>100 \mathrm{mmHg}$ )), (e) pre-existing peripheral neuropathy $\geq$ grade 1 (National Cancer Institute-Common Terminology Criteria for Adverse Events NCI-CTCAE v4.0), (f) history of significant neurological or psychiatric disorders, (g) active infection before registration, (h) major surgery procedure within 28 days prior to registration, (i) severe non-healing wounds, ulcers or bone fractions, ( $\mathrm{j}$ ) evidence of bleeding diathesis or coagulopathy, (k) therapeutic anticoagulation (including aspirin $>325 \mathrm{mg} / \mathrm{d}$ within 10 days before registration); (1) history of thromboembolic events or hemorrhagic disease within 6 months before registration, $(\mathrm{m})$ gastrointestinal perforation, gastrointestinal fistula, intra-abdominal abscess within 6 months before registration, (n) proteinuria (dipstick test $>2+$ requires further assessment with $24 \mathrm{~h}$ urinary protein excretion) and (o) pregnant or breastfeeding women.

Study design. This was a prospective single-arm, multicenter phase II clinical trial to evaluate feasibility and safety of neoadjuvant chemotherapy with capecitabine, oxaliplatin and bevacizumab followed by concomitant standard chemoradiation with capecitabine and TME in patients with MRI-defined high-risk LARC. Secondary end-points included downstaging, pathologic response and evaluation of postoperative morbidity according to Accordion severity grading system (22). Clinical examination, computer tomography (CT) of the entire thorax and abdomen, pelvic MRI, urine test and standard laboratory work-up were undertaken within 28 days of study entry.

Neoadjuvant chemotherapy. Patients were treated with 3 cycles of neoadjuvant chemotherapy. Capecitabine was administered at $1,000 \mathrm{mg} / \mathrm{m}^{2}$ b.i.d. during the first 9 weeks (days 1-14, 22-35, 4356). Oxaliplatin was administered at $130 \mathrm{mg} / \mathrm{m}^{2}$ as a 2- to 6-hour intravenous infusion on days 1,22 and 43 ( \pm 2 days). Toxicities were assessed and recorded at every visit and graded (grade 1-4) according to NCI CTCAE version 4.0 (23). The capecitabine and oxaliplatin dose modification schemes were applied if patients experienced grade 2-4 toxicities. Dose modification was not required for toxicities that were considered unlikely to become serious or life-threatening (e.g., alopecia). Bevacizumab was administered by a 90 -min intravenous infusion at $7.5 \mathrm{mg} / \mathrm{kg}$ body weight on day 1,22 and 43 ( \pm 2 days). If the first infusion was tolerated, the second infusion was given in $60 \mathrm{~min}$ and all subsequent infusions over 30 minutes if 60 -min infusion was tolerated. Dose reduction for toxicity was not recommended but dosing with bevacizumab was hold or discontinued for defined AEs.

Concomitant chemoradiation. Concomitant chemoradiation followed one week after completion of neoadjuvant chemotherapy. Radiotherapy was performed using a linear accelerator for $>4 \mathrm{MeV}$ photons. A computer plan was based on the CT scan in the same position. A threefield technique with lateral wedge filters was employed. Individualized blockings were used to protect lateral field corners, dorsal soft tissues (skin, rima ani) and, if necessary, cranial ventral parts of the small intestine. The upper field border was positioned at level L5-S1, depending on the location of the primary tumor. The ventral border depended on the location of the tumor and its degree of infiltration into the surrounding structures. Radiation therapy was delivered 5 days a week for 5 weeks with a fractionation of $1.8 \mathrm{~Gy}$ to the reference point (isocenter). Total dose in the reference point was $45 \mathrm{~Gy}$. Radiation was discontinued if grade 4 toxicities occurred, according to the NCI CTC 
version 4.0 guidelines. Capecitabine was administered concurrently at $825 \mathrm{mg} / \mathrm{sqm}$ b.i.d. on days of radiation during the first 4 weeks (days $1-5,8-12,15-19,22-26)$.

Surgical resection. Surgical resection followed 2-4 weeks after completion of chemoradiation. The goal of surgical resection was complete removal of the primary tumor according to the principles of TME either by low anterior resection (LAR), inter-sphincter resection (ISR) or abdomino-perineal excision (APE).

Statistical analysis. For the primary end-points, feasibility and safety were evaluated descriptively. Variables of interest were number of patients with toxicities grade 3-4 and number of therapy breaks and therapy discontinuations. The statistical analysis was based on the "intention to treat" (ITT) principle, all patients with at least one cycle bevacizumab therapy were included. Missing values in terms of downstaging were interpreted as non-responders (worst case); other missing values were replaced by the last observation carried forward principle.

\section{Results}

Patients' characteristics. A total of 25 patients were accrued into the study in 7 Austrian Institutions from October 2011 through August 2013. Of the patients, 9 (36\%) were women and $16(64 \%)$ men. The median age was 62 years (range $=24$ $78)$. Four patients (16\%) had cT4 tumors and 20 patients $(80 \%)$ cT3 tumors; one patient had cTis tumor. This patient did not take any doses of chemotherapy or any other study therapy and was excluded from ITT analysis due to important protocol deviation on inclusion criteria. All other patients $(n=24)$ had a histologically-proven adenocarcinoma of the rectum. Suspected positive lymph nodes (LN) by imaging were detected in 18 patients $(72 \%)$; in 10 patients $(40 \%) \mathrm{N} 1$ and in 8 patients $(32 \%) \mathrm{N} 2,5$ patients $(6 \%)$ were LN-negative, 2 patients $(8 \%)$ were not evaluable for $\mathrm{N}$-stage. Patients' baseline characteristics are summarized in Table I. All patients had ECOG performance status 0 (100\%).

Adherence to treatment. All ITT patients completed the first cycle of neoadjuvant chemotherapy; $87.5 \%$ and $79.2 \%$ completed the second and third cycles, respectively. Most patients underwent concomitant chemoradiation, with $94.7 \%$ completing all cycles. Among the 20 patients $(83.3 \%)$ who proceeded to surgery, $19(95 \%)$ received the planned neoadjuvant treatment. The remaining patient who underwent surgery without completing the neoadjuvant treatment had only one cycle of neoadjuvant chemotherapy and no concomitant chemoradiation. Figure I shows adherence to the assigned treatment.

Neoadjuvant chemotherapy. Capecitabine was taken orally twice daily during the first 9 weeks (days 1-14, 22-35, 4356). Oxaliplatin and bevacizumab were administered intravenous for 3 cycles (days 1, 22, 43). One patient (4\%)
Table I. Clinical characteristics at baseline.

\begin{tabular}{lc}
\hline Baseline characteristics $(\mathrm{n}=25)$ & \\
\hline Gender; N patients $(\%)$ & $16(64)$ \\
Male & $9(36)$ \\
Female & \\
Age; years & 62 \\
Median & $24-78$ \\
Range & \\
Performance status; No. of patients (\%) & $25(100)$ \\
0 & \\
TMN stage; No. of patients $(\%)$ & $1(4)$ \\
cTis & $20(80)$ \\
cT3 & $4(16)$ \\
cT4 & $5(6)$ \\
cN0 & $10(40)$ \\
cN1 & $8(32)$ \\
cN2 & $2(8)$ \\
cNx & \\
\hline
\end{tabular}

Tis, carcinoma in situ; this patient was excluded from the intention to treat (ITT) population due to important protocol deviation on inclusion criteria.

never started capecitabine, oxaliplatin and bevacizumab therapy due to important protocol deviation, 19 patients finished neoadjuvant chemotherapy as per protocol and 5 had an early end of therapy (EOT) due to AEs. Two of them discontinued therapy after 1 st cycle and three of them after 2nd cycle of treatment. Capecitabine dose was modified during neoadjuvant chemotherapy in 5 patients (in one patient due to gastrointestinal toxicity a dosage reduction of $25 \%$ was done; in 4 patients dose modification was done due to calculation or intake error - in 2 of these patients dosage was increased and not reduced due to intake error). Three patients had an interruption of capecitabine due to AEs (median=3.5 days), but capecitabine could be restarted. Oxaliplatin dose reduction of $25 \%$ was done in one patient due to gastrointestinal toxicity.

Concomitant chemoradiation. Radiotherapy with an amount of $45 \mathrm{~Gy}$ in 25 fractions was planned (1.8 Gy daily from Monday to Friday, days 1-33). Capecitabine was administered concurrently at $825 \mathrm{mg} / \mathrm{sqm}$ b.i.d. on days of radiation during the first 4 weeks (days 1-5, 8-12, 15-19, 2226). Nineteen patients finished neoadjuvant chemotherapy as per protocol and all started concomitant chemoradiation. Two patients had capecitabine dose modification during concomitant chemoradiation. In one patient, dose modification was due to hand-food-syndrome and in the other one due to calculation error. Fifteen out of 19 patients (78.9\%) received the total dose of radiation. One patient had an EOT during RT (in week 5) due to toxicity and 3 patients missed 1-5 days of RT due to holiday. 


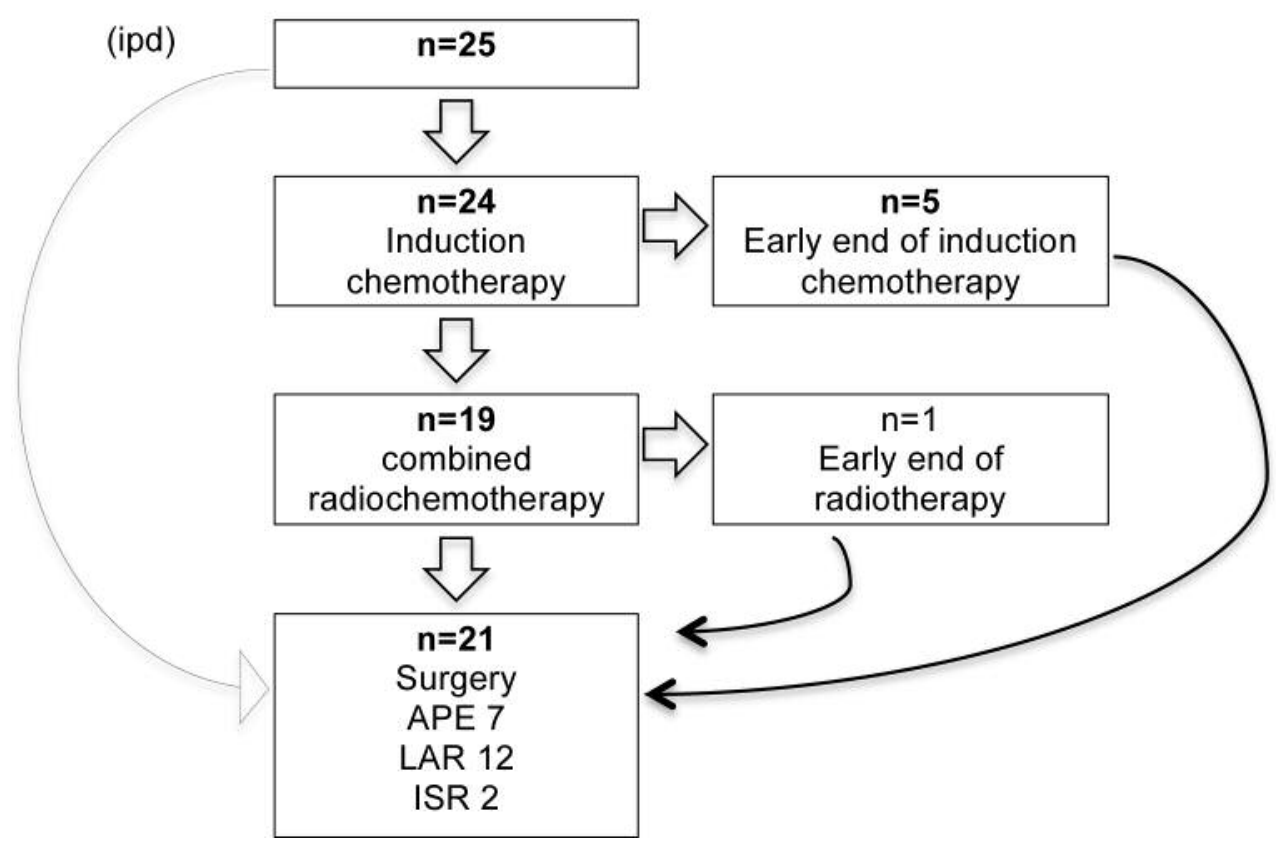

Figure 1. Adherence to treatment assignment. Reasons for early end of therapy (EOT) during induction chemotherapy: one patient due to grade 3 mucositis, one patient due to grade 3 mucositis, diarrhea and grade 4 renal failure, one patient due to allergic reaction, one patient due to diarrhea and febrile neutropenia, one patient due to thrombocytopenia, hypertension and depressed mode. Reason for EOT during chemotherapy (CRT): one patient due to grade 3 skin reaction. APE, Abdomino-perineal excision; LAR, low anterior resection; ISR, inter-sphincter resection; ipd, important protocol deviation.

Surgical resection. Surgical resection followed chemoradiation by a median of 29 days (range=20-109 days) and was performed in 21 patients or 20 ITT patients who started treatment. In 4 patients, surgical resection was not documented due to EOT during first 3 cycles of neoadjuvant chemotherapy. Surgical resection was performed according to the principles of TME either by APE (33.3\%), LAR $(57.1 \%)$ or ISR $(9.5 \%)$.

Efficacy results. Margin-negative (R0) resection was possible in 19 out of 20 patients (95\%). T-downstaging was observed in $54.2 \%(13 / 24)$ of the ITT population. Postoperative histology revealed T-downstaging in 11 out of 18 patients with cT3 tumors who underwent surgical resection. Four patients showed downstaging to ypT2, one patient to ypT1 and six patients to ypT0. Seven out of 18 patients with cT3 remained ypT3. Both patients with cT4 tumor who underwent surgical resection showed T-downstaging to ypT3. Complete pathological remission (pCR) ypT0ypNo was observed in 6 out of 20 operated patients or in $25 \%(6 / 24)$ from the ITT population (Table II). Nodal status (N-stage) tumor downstaging was observed in 10 from 20 operated patients or $41.6 \%$ from ITT population. In four patients $\mathrm{N}$ downstaging was not observed. Four patients were nodal status-negative at baseline; therefore, downstaging was not possible. In two patients nodal status could not be evaluated at baseline and, therefore, $\mathrm{N}$-downstaging was not defined.

Safety results. Grade 3/4 AEs observed in this study are summarized in Table III. Fourteen out of 24 patients experienced at least one grade $3 / 4$ AE (58.3\%). During neoadjuvant chemotherapy, the most frequent grade 3 AEs were diarrhea (16.6\%) and mucositis (12.5\%). Only one grade $4 \mathrm{AE}$ occurred (acute renal failure; $4.2 \%$ ). During standard chemoradiation, grade 3 AEs were skin reaction $(5.3 \%)$ and coronar sclerosis $(5.3 \%)$. There was no grade 4 AE during chemoradiation. Nine patients (45\%) experienced at least one postoperative grade 3 complication. There were two major perioperative complications requiring reintervention (ileus, ileal perforation). Both complications occurred in patients after LAR. Other grade 3 AEs after surgery were hyponatremia (5\%), vomiting $(5 \%)$ and nausea $(5 \%)$. There were no deaths reported during the conduct of the study. Four patients did not finished neoadjuvant chemotherapy due grade 3/4 AEs; one patient due to grade 3 mucositis after first cycle of neoadjuvant chemotherapy; one patient due to grade 4 renal failure and grade 3 mucositis and diarrhea after first cycle of neoadjuvant chemotherapy; one patient due to allergic reaction after first cycle (this patient underwent surgery); one patient due to diarrhea and 
Table II. Overview of pathological responses after neoadjuvant chemoradiation and concomitant chemotherapy.

\begin{tabular}{lcc}
\hline & \multicolumn{2}{c}{ Baseline MRI } \\
\cline { 2 - 3 } & $\begin{array}{c}\text { MRI T3 } \\
(\mathrm{n}=20)\end{array}$ & $\begin{array}{c}\text { MRI T4 } \\
(\mathrm{n}=4)\end{array}$ \\
\hline No surgical resection & 2 & 2 \\
Pathological staging after surgical resection & 6 & 0 \\
$\quad$ ypT0 & 1 & 0 \\
ypT1 & 4 & 0 \\
ypT2 & 7 & 2 \\
$\quad$ ypT3 & 11 & 2 \\
T-downstaging & 7 & 0 \\
T stage unchanged & & \\
\hline
\end{tabular}

MRI, Magnetic resonance imaging.

febrile neutropenia after second cycle. One patient had EOT after two cycles of neoadjuvant chemotherapy due to grade 2 AEs (thrombocytopenia, hypertension, depressed mode) and grade 1 AEs (epistaxis, fatigue). One patient had EOT after 4 weeks of chemotherapy due to grade 3 skin reaction.

\section{Discussion}

In this study, the administration of 3 cycles of neoadjuvant chemotherapy with bevacizumab, oxaliplatin and capecitabine followed by concomitant standard chemoradiation resulted in a pCR rate of $25 \%$, T-downstaging in $54.2 \%$ and $\mathrm{R} 0$ resection in $95 \%$ of the of the ITT population. Most AEs occurred during neoadjuvant chemotherapy, however, nearly $80 \%$ of patients have completed all cycles of neoadjuvant chemotherapy. Major postoperative complications were reported from 2 patients requiring re-intervention.

Neoadjuvant chemoradiation followed by TME and adjuvant chemotherapy is the standard treatment for LARC (1). This approach offers a number of benefits, such as tumor downsizing, a higher rate of sphincter preservation (2) and reduced local recurrence but without consistent impact on disease-free survival (DFS) and OS (2-4, 24). Studies of fluoropyrimidine-based chemoradiation achieved $\mathrm{pCR}$ rates of $8-19 \%(10,25-27)$. Despite improved local therapy, the development of local recurrence in $10 \%$ and the occurrence of distant metastases in $25-30 \%$ are still serious problems in LARC. Furthermore, the administration of adjuvant chemotherapy, which is a standard treatment with established benefit in colon cancer, is more difficult in LARC. Less than $50 \%$ of LARC patients complete all cycles of adjuvant chemotherapy due to toxicities and patient refusal $(28,29)$ and this may compromise DFS and OS. Efforts to improve these results have focused on intensification of neoadjuvant
Table III. Grade $3 / 4$ adverse events reported during study trial (according to NCI CTCAE version 4.0).

\begin{tabular}{|c|c|c|c|}
\hline \multirow[b]{2}{*}{ Toxicity } & \multicolumn{3}{|c|}{ No. of patients (\%) } \\
\hline & Grade 3 & Grade 4 & Total \\
\hline \multicolumn{4}{|c|}{ Neoadjuvant chemotherapy $(n=24)$} \\
\hline Abdominal pain & $1(4.2)$ & & $1(4.2)$ \\
\hline Acute renal failure & & $1(4.2)$ & $1(4.2)$ \\
\hline Allergic reaction & $1(4.2)$ & & $1(4.2)$ \\
\hline Blood glucose increase & $1(4.2)$ & & $1(4.2)$ \\
\hline Bronchospasm & $1(4.2)$ & & $1(4.2)$ \\
\hline Deep vein thrombosis & $1(4.2)$ & & $1(4.2)$ \\
\hline Diarrhoea & $4(16.6)$ & & $4(16.6)$ \\
\hline Febrile neutropenia & $1(4.2)$ & & $1(4.2)$ \\
\hline Hand-food-syndrom & $1(4.2)$ & & $1(4.2)$ \\
\hline Hypokalemia & $1(4.2)$ & & $1(4.2)$ \\
\hline Mucositis & $3(12.5)$ & & $3(12.5)$ \\
\hline Pancreatitis & $1(4.2)$ & & $1(4.2)$ \\
\hline Polyneuropathy & $1(4.2)$ & & $1(4.2)$ \\
\hline \multicolumn{4}{|c|}{ Concomidant chemoradiotherapy $(n=19)$} \\
\hline Coronar sclerosis & $1(5.3)$ & & $1(5.3)$ \\
\hline Skin reaction & $1(5.3)$ & & $1(5.3)$ \\
\hline \multicolumn{4}{|l|}{ Surgery $(n=20)$} \\
\hline Hyponatremia & $1(5)$ & & $1(5)$ \\
\hline Ileal perforation & $1(5)$ & & $1(5)$ \\
\hline Ileus & $1(5)$ & & $1(5)$ \\
\hline Nausea & $1(5)$ & & $1(5)$ \\
\hline Vomoting & $1(5)$ & & $1(5)$ \\
\hline
\end{tabular}

chemoradiation regimens or neoadjuvant chemotherapy following chemoradiation. The addition of oxaliplatin to standard fluoropyrimidine-based chemoradiation significantly increased toxicities without improving pCR rates, DFS and OS $(8-13,30,31)$. Only the CAO/ARO/AIO-04 trial demonstrated a significant improvement in pCR rates and 3year DFS with addition of oxaliplatin to standard chemoradiation $(32,33)$. Targeted therapies have rapidly gained attraction in the treatment of advanced colorectal cancer. Bevacizumab demonstrated efficacy with significant improvement in PFS and OS in patients with metastatic colorectal cancer (34-36). Adding bevacizumab to standard chemoradiation provides encouraging $\mathrm{pCR}$ rates of $16-32 \%$, but the results are limited to variable toxicities and a relative small number of patients (14-16). Recently, our study group showed in the ABCSG R04-Study several major side-effects ( $25 \%$ of patients with grade $\geq 3$ hemorrhagic events and diarrhea) by the addition of bevacizumab to standard chemoradiation (14). Therefore, the study was stopped after interim analyses on 8 patients. A few trials investigated the 
application of concomitant bevacizumab, capecitabine, oxaliplatin and RT in LARC (37-39). Pathological complete remission was seen in $17-18.4 \%$ of patients. About half of patients experienced postoperative complications.

However, multivariate analyses confirmed that response to neoadjuvant chemoradiation was predictive of improved OS (7, 40-44). Thus, research is focused on neoadjuvant chemotherapy followed by chemoradiation. Potential advantage of this approach includes the early treatment of distant micrometastases, initial downstaging of the primary tumor, administration of chemotherapy at full systemic doses and improved compliance. It is possible that this new approach leads to prolonged DFS and OS, but phase III trials are currently lacking. Several phase II studies evaluated the role of neoadjuvant chemotherapy with Xeloda ${ }^{\circledR}$ (capecitabine) and oxaliplatin (CAPOX) or oxaliplatin + 5-fluorouracil (FOLFOX) followed by chemoradiation and surgical resection $(19,45-50)$. This approach achieved pCR rates of 14-29\%. Although induction chemotherapy with CAPOX did not appear to improve downstaging, tumor regression and pCR rates, this approach achieved a better toxicity profile and improved compliance, as well as a good local control and promising rates of DFS and OS $(46,48)$ compared to intensification of neoadjuvant chemoradiation with oxaliplatin.

Encouraging pCR rates of $16-32 \%$ with the addition of bevacizumab to fluoropyrimidine-based chemoradiation with or without oxaliplatin (14-16, 37-39) and a better toxicity profile and improved compliance with neoadjuvant chemotherapy followed by chemoradiation led us to investigate the addition of bevacizumab to neoadjuvant chemotherapy followed by standard chemoradiation and TME in this ABCSG R05-Study. Due to increased postoperative complications with bevacizumab-based chemoradiation in several trials $(15,16)$, we did not administer bevacizumab during chemoradiation. Due to the intensification of the neoadjuvant therapy, we only included patients with high risk of recurrence.

To our knowledge, there has not been any other trial investigating bevacizumab plus capecitabine and oxaliplatin followed by standard chemoradiation in LARC before. Study design and treatment schedule in our trial are slightly different from other trials. Nogue et al. (51) evaluated in the AVACROSS trial the efficacy and toxicity of four cycles of bevacizumab plus capecitabine and oxaliplatin induction therapy followed by concomitant bevacizumab plus capecitabine-based chemoradiation and TME in a phase II study in 47 patients with MRI-defined poor-prognosis LARC. They observed a pCR rate of $36 \%$ with $\mathrm{R} 0$-resection rate of $98 \%$. Most grade $3 / 4$ AEs occurred during induction phase and included diarrhea (11\%), asthenia (4\%), neutropenia $(6 \%)$ and thrombocytopenia (4\%). Eleven patients $(24 \%)$ required surgical re-intervention. Dipetrillo et al. (52) evaluated bevacizumab with modified FOLFOX followed by concurrent bevacizumab plus FOLFOX and RT. Twenty percent of patients had a pCR, but the increased toxicity profile with grade $3 / 4$ toxicities in $76 \%$ of patients and postoperative complications in $36 \%$ led to early termination of the study. Xiao et al. (53) investigated the safety and efficacy of one cycle induction therapy with bevacizumab and FOLFOX followed by concurrent chemoradiation with bevacizumab and 5-fluorouracil (5-FU) and one cycle of consolidation chemotherapy with FOLFOX after chemoradiation. Complete pathologic remission was achieved in $39.1 \%$ of patients; 3-year DFS and 3-year OS were $72.5 \%$ and $95 \%$. During neoadjuvant therapy, grade 4 hematological toxicities and grade 3 non-hematological toxicities occurred in $12 \%$ and $48 \%$. Postoperative complications were seen in $21.7 \%$ of patients.

Compared with the results of the AVACROSS trial, our trial demonstrated a comparable grade $3 / 4$ toxicity profile with the exception of mucositis during neoadjuvant chemotherapy. In our trial, no deaths were reported, whereas, in the AVACROSS trial, 2 deaths occurred during neoadjuvant chemotherapy. Postoperative complication rates (45\% versus $58 \%$ ) and surgical re-interventions (10\% versus $24 \%$ ) were lower in our study. In our trial, there was only one postoperative abscess grade 2 and no wound infection or anastomotic leak. This is probable due to the fact that, in our trial, no bevacizumab was given during chemoradiation. However, pCR with $25 \%$ was lower than expected, in our trial, compared with the other trials using a quite similar regimen. An important strength of this study is that we only included patients with MRI-defined cT3NxM0 or cT4NxM0 adenocarcinoma of the rectum. Therefore, downstaging is more difficult in this homogenous patient group with high risk of recurrence than in other trials that included also patients with cT1-4N1-2 tumors $(52,53)$. A limitation of our study is the short interval between neoadjuvant treatment and surgery (median=29 days) compared with the AVACROSS trial using an interval of 6-8 weeks between neoadjuvant treatment and TME. This may explain the lower pCR rate in our study.

The results of this study suggest that neoadjuvant chemotherapy with bevacizumab, capecitabine and oxaliplatin followed by concomitant standard chemoradiation is feasible in patients with high-risk LARC and resulted in pCR rate of $25 \%$ and neoadjuvant chemotherapy completion rate of $80 \%$. Further studies are required to define the impact of bevacizumab in the neoadjuvant setting of LARC on DFS and OS.

\section{Conclusion}

This study suggests that neoadjuvant chemotherapy with bevacizumab, capecitabine and oxaliplatin followed by 
concomitant standard chemoradiation is feasible in patients with high-risk LARC and resulted in a pCR rate of $25 \%$ and neoadjuvant chemotherapy completion rate of $80 \%$.

\section{Conflicts of interest}

None.

\section{References}

1 National Comprehensive Cancer Network Home Page. http://www.ncen.org/ (NCCI guidelines version 1.2015).

2 Sauer R, Liersch T, Merkel S, Fietkau R, Hohenberger W, Hess C, Becker H, Raab HR, Villanueva MT, Witzigmann H, Wittekind C, Beissbarth T and Rödel C: Preoperative versus postoperative chemoradiotherapy for locally advanced rectal cancer: Results of the German CAO/ARO/AIO-94 randomized phase III trial after a median follow-up of 11 years. J Clin Oncol 30: 1926-1933, 2012.

3 Gérard JP, Conroy T, Bonnetain F, Bouché O, Chapet O, ClosonDejardin MT, Untereiner M, Leduc B, Francois E, Maurel J, Seitz JF, Buecher B, Mackiewicz R, Ducreux M and Bedenne L: Preoperative radiotherapy with or without concurrent fluorouracil and leucovorin in T3-4 rectal cancers: Results of FFCD 9203. J Clin Oncol 24: 4620-4625, 2006.

4 Bosset JF, Calais G, Mineur L, Maingon P, Radosevic-Jelic L, Daban A, Bardet E, Beny A, Briffaux A and Collette L: Enhanced tumorocidal effect of chemotherapy with preoperative radiotherapy for rectal cancer: Preliminary results - EORTC 22921. J Clin Oncol 23: 5620-5627, 2005.

5 Bosset JF, Collette L, Calais G, Mineur L, Maingon P, Radosevic-Jelic L, Daban A, Bardet E, Beny A and Ollier JC: Chemotherapy with preoperative radiotherapy in rectal cancer. N Engl J Med 355: 1114-1123, 2006.

6 Folkesson J, Birgisson H, Pahlman L, Cedermark B, Glimelius B and Gunnarsson U: Swedish Rectal Cancer Trial: Long lasting benefits from radiotherapy on survival and local recurrence rate. J Clin Oncol 23: 5644-5650, 2005.

7 van Gijn W, Marijnen CA, Nagtegaal ID, Kranenbarg EM, Putter H, Wiggers T, Rutten HJ, Påhlman L, Glimelius B and van de Velde CJ: Preoperative radiotherapy combined with total mesorectal excision for resectable rectal cancer: 12-year followup of the multicentre, randomised controlled TME trial. Lancet Oncol 12: 575-582, 2011.

8 Aschele C, Cionini L, Lonardi S, Pinto C, Cordio S, Rosati G, Artale S, Tagliagambe A, Ambrosini G, Rosetti P, Bonetti A, Negru ME, Tronconi MC, Luppi G, Silvano G, Corsi DC, Bochicchio AM, Chiaulon G, Gallo M and Boni L: Primary tumor response to preoperative chemoradiation with or without oxaliplatin in locally advanced rectal cancer: Pathologic results of the STAR-01 randomized phase III trial. J Clin Oncol 29: 2773-2780, 2011.

9 Gérard JP, Azria D, Gourgou-Bourgade S, Martel-Lafay I, Hennequin C, Etienne PL, Vendrely V, François E, de La Roche G, Bouché O, Mirabel X, Denis B, Mineur L, Berdah JF, Mahé MA, Bécouarn Y, Dupuis O, Lledo G, Seitz JF, Bedenne L, Juzyna B and Conroy T: Clinical outcome of the ACCORD 12/0405 PRODIGE 2 randomized trial in rectal cancer. J Clin Oncol 30: 4558-4565, 2012.
10 Roh MS, Yothers GA, O'Connell MJ, Beart RW, Pitot HC, Shields AF, Parda DS, Sharif S, Allegra CJ, Petrelli NJ, Landry JC, Ryan DP, Arora A, Evans TL, Soori GS, Chu L, Landes RV, Mohiuddin M, Lopa S and Wolmark N: The impact of capecitabine and oxaliplatin in the preoperative multimodality treatment of patients with carcinoma of the rectum: NSABP R04. J Clin Oncol 29suppl: abstract 3503, 2011.

11 O'Connell MJ, Colangelo LH, Beart RW, Petrelli NJ, Allegra CJ, Sharif S, Pitot HC, Shields AF, Landry JC, Ryan DP, Parda DS, Mohiuddin M, Arora A, Evans LS, Bahary N, Soori GS, Eakle J, Robertson JM, Moore DF Jr, Mullane MR, Marchello BT, Ward PJ, Wozniak TF, Roh MS and Yothers G: Capecitabine and oxaliplatin in the treatment of rectal cancer: Surgical end points from national surgical adjuvant breast and bowel project trial R04. J Clin Oncol 32: 1927-1934, 2014.

12 Schmoll HJ, Haustermans K, Price TJ, Nordlinger B, Hofheinz $\mathrm{R}$, Daisne JF, Janssens J, Brenner B, Schmidt P, Reinel H, Hollerbach S, Caca K, Fauth FWB, Hannig C, Zalcberg JR, Tebbutt NC, Mauer ME, Messina CGM, Lutz MP and Van Cutsem E: Preoperative chemoradiotherapy and postoperative chemotherapy with capecitabine and oxaliplatin versus capecitabine alone in locally advanced rectal cancer: First results of the PETACC-6 randomized trial. J Clin Oncol 31suppl: abstract 3531, 2013.

13 Schmoll HJ, Stein A, Hofheinz RD, Price TJ, Nordlinger B, Daisne JF, Daisne JF, Janssens J, Brenner B, Schmidt P, Reinel H, Hollerbach S, Caca K, Fauth F, Zalcberg J, Marreaud S, M. Mauer M, M. Lutz M, E. Van Cutsem E and Haustermans K: Preoperative chemoradiotherapy and postoperative chemotherapy with capecitabine and oxaliplatin vs. capecitabine alone in locally advanced rectal cancer: Final analyses. Ann Oncol 27: 149-206, 2016.

14 Resch G, De Vries A, Öfner D, Eisterer W, Rabl H, Jagoditsch M, Gnant $\mathrm{M}$ and Thaler J: Preoperative treatment with capecitabine, bevacizumab and radiotherapy for primary locally advanced rectal cancer - A two stage phase II clinical trial. Radiothera Oncol 102: 10-13, 2012.

15 Willett CG, Duda DG, di Tomaso E, Boucher Y, Ancukiewicz M, Sahani DV, Lahdenranta J, Chung DC, Fischman AJ, Lauwers GY, Shellito P, Czito BG, Wong TZ, Paulson E, Poleski M, Vujaskovic Z, Bentley R, Chen HX, Clark JW and Jain RK: Efficacy, safety and biomarkers of neoadjuvant bevacizumab, radiation therapy and fluorouracil in rectal cancer: A multidisciplinary phase II study. J Clin Oncol 27: 3020-3026, 2009.

16 Crane CH, Eng C, Feig BW, Das P, Skibber JM, Chang GJ, Wolff RA, Krishnan S, Hamilton S, Janjan NA, Maru DM, Ellis LM and Rodriguez-Bigas MA: Phase II trial of neoadjuvant bevacizumab, capecitabine and radiotherapy for locally advanced rectal cancer. Int J Radiat Oncol Biol Phys 76: 824830, 2009.

17 Velenik V, Ocvirk J, Oblak I and Anderluh F: A phase II study of cetuximab, capecitabine and radiotherapy in neoadjuvant treatment of patients with locally advanced resectable rectal cancer. Eur J Surg Oncol 36: 244-250, 2010.

18 Chua YJ, Barbachano Y, Cunningham D, Oates JR, Brown G, Wotherspoon A, Tait D, Massey A, Tebbutt NC and Chau I: Neoadjuvant capecitabine and oxaliplatin before chemoradiotherapy and total mesorectal excision in MRI-defined poor-risk rectal cancer: A phase 2 trial. Lancet Oncol 11: 241-248, 2010. 
19 Fernández-Martos C, Pericay C, Aparicio J, Salud A, Safont M, Massuti B, Vera R, Escudero P, Maurel J, Marcuello E, Mengual JL, Saigi E, Estevan R, Mira M, Polo S, Hernandez A, Gallen M, Arias F, Serra J and Alonso V: Phase II, randomized study of concomitant chemoradiotherapy followed by surgery and adjuvant capecitabine plus oxaliplatin (CAPOX) compared with induction CAPOX followed by concomitant chemoradiotherapy and surgery in magnetic resonance imaging-defined, locally advanced rectal cancer: Grupo cancer de recto 3 study. J Clin Oncol 28: 859-865, 2010.

20 Maréchal R, Vos B, Polus M, Delaunoit T, Peeters M, Demetter P, Hendlisz A, Demols A, Franchimont D, Verset G, Van Houtte P, Van de Stadt $J$ and Van Laethem JL: Short course chemotherapy followed by concomitant chemoradiotherapy and surgery in locally advanced rectal cancer: A randomized multicentric phase II study. Ann Oncol 23: 1525-1530, 2012.

21 Fornaro L, Caparello C, Vivaldi C, Rotella V, Musettini G, Falcone A, Baldini E and Masi G: Bevacizumab in the preoperative treatment of locally advanced rectal cancer: A systematic review. World J Gastroenterol 20: 6081-6091, 2014.

22 Strasberg SM, Linehan DC and Hawkins WG: The Accordion severity grading system of surgical complications. Annals of Surgery 250: 177-186, 2009.

23 National Cancer Institute: Common Terminology Criteria for Adverse Events (CTCAE) version 4.0. May 28, 2009.

24 Breugom AJ, Swets M, Bosset JF, Collette L, Sainato A, Cionini L, Glynne-Jones R, Counsell N, Bastiaannet E, van den Broek CB, Liefers GJ, Putter H and van de Velde CJ: Adjuvant chemotherapy after preoperative (chemo) radiotherapy and surgery for patients with rectal cancer: A systematic review and metaanalysis of individual patient data. Lancet Oncol 16: 200-207, 2015.

25 Sauer R, Becker H, Hohenberger W, Rödel C, Wittekind C, Fietkau R, Martus P, Tschmelitsch J, Hager E, Hess CF, Karstens JH, Liersch T, Schmidberger H and Raab R: Preoperative versus postoperative chemoradiotherapy for rectal cancer. N Engl J Med 351: 1731-1740, 2004.

26 Roh MS, Colangelo LH, O'Connell MJ, Yothers G, Deutsch M, Allegra CJ, Kahlenberg MS, Baez-Diaz L, Ursiny CS, Petrelli NJ and Wolmark N: Preoperative multimodality therapy improves disease-free survival in patients with carcinoma of the rectum: NSABP R-03. J Clin Oncol 27: 5124-5130, 2009.

27 Park JH, Yoon SM, Yu CS, Kim JH, Kim TW and Kim JC: Randomized phase 3 trial comparing preoperative and postoperative chemoradiotherapy with capecitabine for locally advanced rectal cancer. Cancer 117: 3703-3712, 2011.

28 Glynne-Jones R, Counsell N, Quirke P, Mortensen N, Maraveyas A, Meadows HM, Ledermann $\mathrm{J}$ and Sebag-Montefiore D: Chronicle: Results of a randomized phase III trial in locally advanced rectal cancer after neoadjuvant chemoradiation randomizing postoperative adjuvant capecitabine plus oxaliplatin (XELOX) versus control. Ann Oncol 25: 1356-1362, 2014.

29 Bosset JF, Calais G, Mineur L, Maingon P, Stojanovic-Rundic S, Bensadoun RJ, Bardet E, Beny A, Ollier JC, Bolla M, Marchal D, Van Laethem JL, Klein V, Giralt J, Clavère P, Glanzmann C, Cellier P and Collette L: Fluorouracil-based adjuvant chemotherapy after preoperative chemoradiotherapy in rectal cancer: Long-term results of the EORTC 22921 randomised study. Lancet Oncol 15: 184-190, 2014.

30 Schmoll HJ, Haustermans K, Price TJ, Nordlinger B, Hofheinz R, Daisne JF, Janssens J, Brenner B, Schmidt P, Reinel H, Hollerbach
S, Caca K, Fauth FWB, Hannig C, Zalcberg JR, Tebbutt NC, Mauer ME, Messina CGM, Lutz MP and Van Cutsem E: Preoperative chemoradiotherapy and postoperative chemotherapy with capecitabine and oxaliplatin versus capecitabine alone in locally advanced rectal cancer: Disease-free survival results at interim analysis. J Clin Oncol 32suppl: abstract 3501, 2014.

31 Allegra CJ, Yothers G, O'Connell MJ, Roh MS, Lopa SH, Petrelli NJ, Beart RW, Sharif S and Wolmark N: Final results from NSABP protocol R-04: Neoadjuvant chemoradiation (RT) comparing continuous infusion (CIV) 5-FU with capecitabine (Cape) with or without oxaliplatin (Ox) in patients with stage II and III rectal cancer. J Clin Oncol 32suppl: abstract 3603, 2014.

32 Rödel C, Liersch T, Becker H, Fietkau R, Hohenberger W, Hothorn T, Graeven U, Arnold D, Lang-Welzenbach M, Raab HR, Sülberg H, Wittekind C, Potapov S, Staib L, Hess C, Weigang-Köhler K, Grabenbauer GG, Hoffmanns H, Lindemann F, Schlenska-Lange A, Folprecht G and Sauer R: Preoperative chemoradiation and postoperative chemotherapy with fluorouracil and oxaliplatin versus fluorouracil alone in locally advanced rectal caner. Initial results of the German CAO/ARO/AIO-04 randomised phase 3 trial. Lancet Oncol 13: 679-687, 2012.

33 Rödel C, Liersch T, Fietkau R, Hohenberger W, Graeven U, Hothorn T, Arnold D, Raab HR, Wittekind C, Hess CF, Staib L, Becker H and Sauer R: Preoperative chemoradiotherapy and postoperative chemotherapy with 5-fluorouracil and oxaliplatin versus 5-fluorouracil alone in locally advanced rectal cancer: Results of the German CAO/ARO/AIO-04 randomized phase III trial. J Clin Oncol 32suppl; abstract 3500, 2014.

34 Kabbinavar F, Hurwitz HI, Fehrenbacher L, Meropol NJ, Novotny WF, Lieberman G, Griffing $S$ and Bergsland E: Phase II randomized trial comparing bevacizumab plus fluorouracil/ leucovorin with FU/LV in patients with metastatic colorectal cancer. J Clin Oncol 21: 60-65, 2003.

35 Hurwitz H, Fehrenbacher L, Novotny W, Cartwright T, Hainsworth J, Heim W, Berlin J, Baron A, Griffing S, Holmgren E, Ferrara N, Fyfe G, Rogers B, Ross R and Kabbinavar F: Bevacizumab plus irinotecan, flurouracil and leucovorin for metastatic colorectal cancer. N Engl J Med 350: 2335-2342, 2004.

36 Saltz LB, Clarke S, Díaz-Rubio E, Scheithauer W, Figer A, Wong R, Koski S, Lichinitser M, Yang TS, Rivera F, Couture F, Sirzén F and Cassidy J: Bevacizumab in combination with oxaliplatin-based chemotherapy as first-line therapy in metastatic colorectal cancer: a randomized phase III study. J Clin Oncol 26: 2013-2019, 2008.

37 Dellas K, Höhler T, Reese T, Würschmidt F, Engel E, Rödel C, Wagner W, Richter M, Arnold D and Dunst J: Phase II trial of preoperative radiochemotherapy with concurrent bevacizumab, capecitabine and oxaliplatin in patients with locally advanced rectal cancer. Radiat Oncol 8: 90, 2013.

38 Kennecke H, Berry S, Wong R, Zhou C, Tankel K, Easaw J, Rao S, Post J and Hay J: Pre-operative bevacizumab, capecitabine, oxaliplatin and radiation among patients with locally advanced or low rectal cancer: a phase II trial. Eur J Cancer 48: 37-45, 2012.

39 Landry JC, Feng Y, Cohen SJ, Staley CA 3rd, Whittington R, Sigurdson ER, Nimeiri H, Verma U, Prabhu RS and Benson AB: Phase 2 study of preoperative radiation with concurrent capecitabine, oxaliplatin, and bevacizumab followed by surgery and postoperative 5-fluorouracil, leucovorin, oxaliplatin (FOLFOX), and bevacizumab in patients with locally advanced rectal cancer: ECOG 3204. Cancer 119: 1521-1527, 2013. 
40 Lee JH, Kim SH, Kim JG, Cho HM and Shim BY: Preoperaive chemoradiotherapy followed by laparoscopic surgery for rectal cancer: Predictors of the tumor response and the long-term oncologic outcomes. Int J Radiat Oncol Biol Phys 81: 431-438, 2011.

41 Janjan NA, Crane C, Feig BW, Cleary K, Dubrow R, Curley S, Vauthey JN, Lynch P, Ellis LM, Wolff R, Lenzi R, Abbruzzese J, Pazdur R, Hoff PM, Allen P, Brown T and Skibber J: Improved overall survival among responders to preoperative chemoradiation for locally advanced rectal cancer. Am J Clin Oncol 24: 107-112, 2001.

42 Ruo L, Tickoo S, Klimstra DS, Minsky BD, Saltz L, Mazumdar M, Paty PB, Wong WD, Larson SM, Cohen AM and Guillem JG: Long-term prognostic significance of extent of rectal cancer response to preoperative radiation and chemotherapy. Ann Surg 36: 75-81, 2002.

43 Valentini V, van Stiphout RG, Lammering G, Gambacorta MA, Barba MC, Bebenek M, Bonnetain F, Bosset JF, Bujko K, Cionini L, Gerard JP, Rödel C, Sainato A, Sauer R, Minsky BD, Collette L and Lambin P: Nomograms for predicting local recurrence, distant metastases, and overall survival for patients with locally advanced rectal cancer on the basis of European randomized clinical trials. J Clin Oncol 29: 3163-3172, 2011.

44 Maas M, Nelemans PJ, Valentini V, Das P, Rödel C, Kuo LJ, Calvo FA, García-Aguilar J, Glynne-Jones R, Haustermans K, Mohiuddin M, Pucciarelli S, Small W Jr, Suárez J, Theodoropoulos G, Biondo S, Beets-Tan RG and Beets GL: Long-term outcome in patients with a pathological complete response after chemoradiation for rectal cancer: A pooled analysis of individual patient data. Lancet Oncol 11: 835-844, 2010.

45 Chau I, Brown G, Cunningham D, Tait D, Wotherspoon A, Norman AR, Tebbutt N, Hill M, Ross PJ, Massey A and Oates $\mathrm{J}$ : Neoadjuvant capecitabine and oxaliplatin followed by synchronous chemoradiation and total mesorectal excision in magnetic resonance imaging-defined poor-risk rectal cancer. J Clin Oncol 24: 668-674, 2006.

46 Fernandez-Martos C, Pericay C, Aparicio J, Safont, MJ, Salud A, Massuti, B Alonso V, Vera R, Escudero P, Martin-Richard M, Bosch C and Maurel J: Chemoradiation (CRT) followed by surgery and adjuvant capecitabine plus oxaliplatin (CAPOX) compared with induction CAPOX followed by concomitant CRT and surgery for locally advanced rectal cancer: Results of the Spanish GCR-3 randomized phase II trial after a median followup of 5 years. J Clin Oncol 32( suppl 3): abstract 383, 2014.

47 Perez K, Pricolo V, Vrees MDiPetrillo TA, Oldenberg N, Klipfel A, Schechter S, Kinsella, TJ, Roth L, Cataldo T, Nhah N, Olszewski AJ, Isdale D, Safran, H and Sikov WM: A phase II study of complete neoadjuvant therapy in rectal cancer (CONTRE): The Brown University Oncology Group. J Clin Oncol 31(suppl 4): abstract 335, 2013.
48 Schou JV, Larsen FO, Rasch L, Linnemann D, Langhoff J, Høgdall E, Nielsen DL, Vistisen K, Fromm A and Jensen BV: Induction chemotherapy with capecitabine and oxaliplatin followed by chemoradiotherapy before total mesorectal excision in patients with locally advanced rectal cancer. Ann Oncol 23: 2627-2633, 2012.

49 Maréchal R, Vos B, Polus M, Delaunoit T, Peeters M, Demetter P, Hendlisz A, Demols A, Franchimont D, Verset G, Van Houtte P, Van de Stadt $J$ and Van Laethem JL: Short course chemotherapy followed by concomitant chemoradiotherapy and surgery in locally advanced rectal cancer: A randomized multicentric phase II study. Ann Oncol 23: 1525-1530, 2012.

50 Koeberle D, Burkhard R, von Moos R, Winterhalder R, Hess V, Heitzmann F, Ruhstaller T, Terraciano L, Neuweiler J, Bieri G, Rust C and Toepfer M: Phase II study of capecitabine and oxaliplatin given prior to and concurrently with preoperative pelvic radiotherapy in patients with locally advanced rectal cancer. Br J Cancer 98: 1204-1209, 2008.

51 Nogué M, Salud A, Vicente P, Arriví A, Roca JM, Losa F, Ponce J, Safont MJ, Guasch I, Moreno I, Ruiz A and Pericay C: Addition of bevacizumab to XELOX induction therapy plus concomitant capecitabine-based chemoradiotherapy in magnetic resonance imaging-defined poor-prognosis locally advanced rectal cancer: The AVACROSS study. The Oncologist 16: 614620, 2011.

52 Dipetrillo T, Pricolo V, Lagares-Garcia J, Vrees M, Klipfel A, Cataldo T, Sikov W, McNulty B, Shipley J, Anderson E, Khurshid H, Oconnor B, Oldenburg NB, Radie-Keane K, Husain $\mathrm{S}$ and Safran H: Neoadjuvant bevacizumab, oxaliplatin, 5fluorouracil, and radiation for rectal cancer. Int J Radiat Oncol Biol Phys 82: 124-129, 2012.

53 Xiao J, Chen Z, Li W, Yang Z, Huang Y, Zheng J, Deng Y, Wang L, Ren D, Peng J, Lan P and Wang J: Sandwich-like neoadjuvant therapy with bevacizumab for locally advanced rectal cancer: A phase II trial. Cancer Chemother Pharmacol 76(1): 21-27, 2015.

Received March 19, 2017

Revised April 3, 2017

Accepted April 4, 2017 